\title{
Pembentukan Konsep Keintiman Berdsarkan Social Information Processing Theory pada Komunitas Sehatmental.id
}

\author{
Casey Catherina, Rino F. Boer, Mei Talia, Stephanie Cecilia \\ Program Studi Ilmu Komunikasi London School of Public Relations - Jakarta \\ E-mail: casey.catherina@gmail.com
}

DOI: https://doi.org/10.21107/ilkom.v14i1.6035

\begin{abstract}
ABSTRAK
Kesehatan mental telah menjadi isu global di berbagai negara sehingga diperlukan penanganan yang serius terhadap isu ini. Di Indonesia sendiri, masyarakat yang mengalami gangguan mental semakin meningkat tajam. Sejalan dengan meningkatnya jumlah komunitas di media sosial yang menyuarakan pentingnya kesehatan mental, ada optimisme bahwa upaya kesehatan mental dapat dilakukan juga melalui media sosial. Namun, benarkah media sosial dapat membangun semangat volunteer (ingin ikut terlibat secara langsung) karena keintiman yang terjalin didalamnya? Berdasarkan uraian tersebut, penelitian ini dilakukan untuk mengetahui konsep keintiman yang terbentuk dalam gerakan sosial kesehatan mental berdasarkan social information processing theory. Penelitian ini menggunakan konsep keintiman dari teori social information processing oleh Joseph Walther. Penelitian ini menggunakan pendekatan kualitatif dengan metode studi kasus pada individu individu di Komunitas Sehatmental.id. Pengumpulan data dilakukan dengan wawancara mendalam terhadap 7 informan dari Komunitas Sehatmental.id. Hasil penelitian ini menunjukkan bahwa keintiman tidak terjadi pada individu - individu di Komunitas Sehatmental.id. Hubungan yang terbentuk bersifat impersonal karena hanya berfokus pada peran masing - masing anggota di dalam komunitas dan kegiatan yang akan dilaksanakan. Hal ini berdampak pada anggota volunter yang sering berganti - ganti di dalam Komunitas Sehatmental.id. Kecepatan respon yang diberikan saat berinteraksi pun tidak membuat anggota komunitas merasa lebih dekat satu sama lain. Hasil penelitian menunjukkan penggunaan kata "kita" atau "kamu" dapat membuat followers merasa dilibatkan. Namun, interaksi di media sosial sering kali dirasa tidak cukup sehingga perlu dilakukan pertemuan tatap muka di antara anggota dengan pengurus.
\end{abstract}

Kata kunci : gerakan sosial, keintiman; kesehatan mental; media sosial; public relations

\section{ABSTRACT}

Mental health has become a global issue in many countries requiring serious treatment of this issue. In Indonesia, the number of people who suffer from emotional mental disorders is increasing. Therefore, any attempt to build an environment that supports mental health should be supported. In line with the increasing number of social communities focused on mental health, there is an optimism that the mental health efforts can be done through social media. Relationships between individuals on social media is expected to bring all people closer so that everyone is able to provide support to one another. In the study, the relationship between individuals on social media is examined using intimacy concept of social information processing theory by Joseph Walther. The study used a qualitative approach with case study method on Sehatmental.id community. Data collection is done by interviewing 7 informants from Sehatmental.id community. The results of this study indicate that intimacy does not happen to people - people relations in the community. The relationships formed is impersonal because it only focuses on the role of each members in the community. Speed of response given also does not make members feel closer to each other. Result of this study also indicates the use of words like "we" or "you" in digital public relations activity on social media are able to make followers feel included in a social movement. However, there is a need for face - to-face meetings between the members.

Keywords: intimacy, mental health, social movement, social media, public relations

Article History:

Received December, $9^{\text {th }} 2019$, Acepted January, $9^{\text {th }} 2020$ 


\section{PENDAHULUAN}

Apakah ada definisi tentang kompetensi komunikasi antarbudaya secara umum? Ataukah setiap budaya memiliki pengertiannya masing-masing secara khusus). Kompetensi komunikasi antar budaya merupakan kebudayaan umum dan

Kesehatan adalah hal yang penting bagi kelangsungan hidup manusia. Dalam Undang - Undang Kesehatan no 36 tahun 2009 dijelaskan bahwa "kesehatan adalah keadaan sehat, baik secara fisik, mental, spritual maupun sosial yang memungkinkan setiap orang untuk hidup produktif secara sosial dan ekonomis". Berdasarkan definisi tersebut dapat dikatakan bahwa sehat secara mental sama pentingnya dengan kesehatan fisik bagi hidup manusia. Bahkan pada tahun 2018, World Health Organization kembali menegaskan bahwa kesehatan mental merupakan bagian yang esensial dalam kesehatan itu sendiri.

Kesehatan mental telah menjadi isu global di berbagai negara sehingga diperlukan penanganan yang serius terhadap isu ini. Di Indonesia, prevalensi penduduk yang mengalami gangguan mental secara emosional meningkat 3,8\% sejak tahun 2013. Di tahun 2018, prevalensi penduduk yang mengalami gangguan mental secara emosional adalah 9,8 persen (Kementerian Kesehatan Republik Indonesia, 2018). Riset Kesehatan Dasar tahun 2013 mendefinisikan gangguan mental secara emosional sebagai keadaan seseorang yang mengalami perubahan secara psikologis (Kementerian Kesehatan Republik Indonesia, 2013). Berdasarkan definisi tersebut, gangguan mental secara emosional dapat dialami oleh siapa saja yang mengalami perubahaan pada aspek psikologi dan dapat berlanjut menjadi gangguan yang lebih serius yang disebut sebagai gangguan jiwa berat. Dari sudut pandang pemerintah, gangguan jiwa berat membutuhkan biaya penanganan yang besar (Kementerian Kesehatan Republik Indonesia, 2013).
Terdapat banyak faktor yang dapat mempengaruhi kesehatan mental. Putri, Wibawa \& Gutama (2015) memaparkan bahwa tuntutan hidup dan stress berlebihan dapat berdampak pada kesehatan mental. Masyarakat Indonesia masih perlu pengetahuan mengenai masalah kesehatan mental karena minimnya informasi mengenai isu tersebut. Dukungan dari masyarakat merupakan hal penting bagi penderita namun disisi lain, masih banyak kejadian penanganan yang tidak tepat untuk penderita gangguan mental karena minimnya informasi mengenai isu kesehatan mental. Hal ini didukung oleh penelitian Choresyo, Nulhaqim dan Wibowo (2015) yang menyebutkan bahwa kurangnya kesadaran dan pengetahuan masyarakat tentang penyakit atau kelainan mental seringkali menimbulkan perlakuan yang salah terhadap penderita penyakit mental. Masih banyak masyarakat yang menjauhi, mengolok - olok bahkan memasung penderita gangguan kesehatan mental. Citra negatif terhadap penderita pun masih melekat di masyarakat dimana penderita dikenal sebagai "sakit jiwa" atau "gila" sehingga penderita dianggap memalukan bagi masyarakat.

Melihat luasnya penyebaran penderita gangguan kesehatan mental di seluruh wilayah Indonesia, salah satu altenatif penanganan isu ini adalah dengan memanfaatkan media sosial. Di media sosial sendiri terdapat beberapa komunitas seperti Komunitas Sehatmental.id (dikenal juga sebagai Komunitas Sehat Mental Indonesia), Into the Light, Get Happy, Depression Warriors Indonesia dan lainnya yang aktif menyuarakan pentingnya kesadaran kesehatan mental. Sejalan dengan meningkatnya jumlah komunitas di media sosial, ada optimisme bahwa upaya kesehatan mental dapat dilakukan juga melalui media sosial. Salah satu komunitas yang aktif dan konsisten dalam menyuarakan pentingnya kesehatan mental adalah Komunitas Sehatmental.id. 


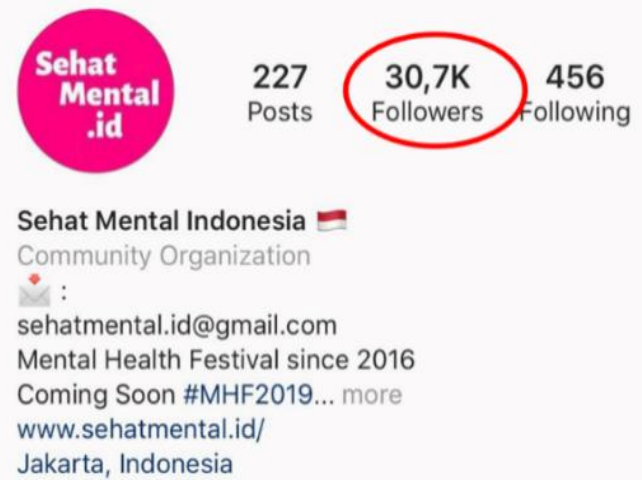

Gambar 1. :Followers Komunitas Sehatmental.id Sumber: Sehat Mental Indonesia, n.d-a

Komunitas Sehatmental.id merupakan salah satu komunitas kesehatan mental yang memiliki followers terbanyak di Instagram yaitu 30.000 followers. Selain itu, komunitas ini juga menggagas ide kegiatan free mental check-up dan Mental Health Fest yang kemudian mendapatkan dukungan dari komunitas kesehatan mental lainnya. Komunitas ini pun membangun hubungan secara online dengan memanfaatkan Whatsapp untuk berkomunikasi dengan para volunternya dan memanfaatkan Line untuk free online counseling. Walaupun interaksi antar anggota komunitas lebih banyak dilakukan secara online, komunitas berhasil mendapatkan partisipasi masyarakat dengan adanya anggota volunter yang berasal dari Jakarta, Bandung dan Malang untuk kegiatan Mental Health Fest yang secara rutin diadakan setiap tahunnya (2016-2018). Masyarakat pun menunjukkan respon positif terhadap gerakan sosial yang dilakukan Komunitas Sehatmental.id dilihat dengan meningkatnya jumlah pengunjung Mental Health dari tahun ke tahun.

Namun demikian, berkomunikasi melalui media sosial tidaklah sama dengan komunikasi tatap muka apalagi dalam membangun semangat voluntarism dari para relawan untuk turut mengambil bagian sebagai panitia lokal dalam event yang mau dilakukan. Walther (1992) melalui teori social information processing memaparkan bahwa keberadaan computer mediated communication (selanjutnya disebut sebagai $\mathrm{CMC}$ ) dapat digunakan untuk membangun hubungan dengan sepenuhnya mengandalkan pesan teks. Teori ini memaparkan bahwa hubungan akan setara dengan komunikasi face to face (selanjutnya disebut $\mathrm{FtF}$ ) seiring berjalannya waktu dan pertukaran informasi personal yang terjadi. Kehadiran media sosial juga mempengaruhi praktik public relations dalam berkomunikasi. Motion, Heath dan Leitch (2016) menyebutkan beberapa tipe media sosial yang dapat dimanfaatkan oleh praktisi public relations yaitu, social networks (Facebook), microblogging (Twitter), video services (YouTube, Vine, Instagram) dan tipe - tipe lainnya. Untuk itu, sewajarnya media sosial juga dapat digunakan untuk membangun semangat volunteer (ingin ikut terlibat secara langsung) karena keintiman yang terjalin antara pengelola media sosial dan anggota. Langkanya penelitian yang mencoba mengkaji terjadinya konsep keintiman di media sosial juga mendorong dipilihnya topik ini.

Berdasarkan fenomena tersebut, penelitian ini bertujuan untuk mengetahui sejauh mana konsep keintiman berdasarkan social information processing dapat terbentuk di media sosial? Kajiannya dilakukan terhadap Komunitas Sehatmental.id di Indonesia.

\section{Teori Social Information Processing}

Social information processing menjelaskan bagaimana membangun hubungan berdasarkan interaksi yang dilakukan pada CMC. Istilah CMC sendiri meluas menjadi internet mediated communication (selanjutnya disebut IMC) dikarenakan komunikasi tidak hanya sebatas pada komputer saja tetapi meluas pada perangkat internet lainnya (Bodomo, 2010).

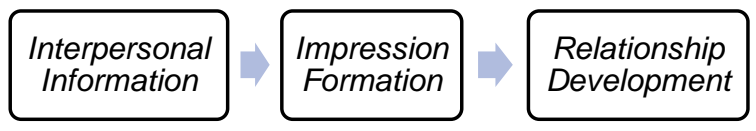

Gambar 2: Teori Social Information Processing oleh Joseph Walther Sumber: Griffin 2011,p 139 
Interpersonal information adalah tahapan awal dimana kedua pihak saling berusaha untuk mengetahui informasi satu sama lain. Walther (1992) berpendapat bahwa informasi interpersonal yang disampaikan di CMC akan memakan waktu lebih lama. Namun, seiring dengan berjalan waktu saat berinteraksi, pertukaran interpersonal messages akan terjadi. Informasi interpersonal akan mengungkapkan mengenai persons and their characteristics dan attitudes.

\section{Pang, Shin, Lew dan Walther (2016) dalam penelitiannya mengungkapkan komunikator berusaha untuk memperkenalkan dirinya serta menentukan topik yang akan dibicarakannya. Selain itu, dalam menunjukkan karakter (charateristics) dapat dilihat pada kata - kata yang digunakan dalam menyampaikan karakter yang diinginkan, misalnya melalui pemilihan kata - kata untuk yang menunjukkan profesional knowledge komunikatornya. Walther (dalam Griffin, 2011) juga menyampaikan bahwa hubungan dapat berkembang dengan menemukan kesamaan (similarities).}

Impression formation ialah tahapan membentuk kesan dan menciptakan gambaran tentang satu sama lain. Pada proses pertukaran interpersonal information tersebut, isyarat nonverbal seperti ekspresi wajah, kedekatan fisik, nada suara, jarak, posisi tubuh, penampilan, gerakan, sentuhan, dan lainnya menjadi hilang. Untuk itu, Walther (dalam Griffin, 2011) menyebutkan 2 fitur dari CMC yang menjadi dasar bagi teori social information processing dalam membentuk sebuah impression, yaitu:

a. Verbal cues dimaksudkan bahwa receivers dapat membentuk kesan terhadap komunikator berdasarkan pesan tertulis (verbal) yang diterima.

b. Extended time dimaksudkan bahwa sender dan receiver membutuhkan waktu yang lebih lama untuk membentuk kesan terhadap satu sama lain secara online maka untuk membangun hubungan dibutuhkan pengiriman pesan yang intens terhadap satu sama lain.
Dengan saling bertukar pesan satu sama lain, impression dapat terbentuk walaupun memerlukan waktu yang lebih lama dari interaksi $\mathrm{FtF}$.

Relationship development merupakan tahapan dimana hubungan kedua pihak yang berinteraksi akan berkembang semakin dekat jika mereka menyukai gambaran yang saling dibentuk. Walther (dalam Griffin, 2011) menyatakan bahwa keintiman dalam komunikasi berbasis komputer dapat dilihat dari anticipated future interaction dan chronemics yaitu:

a. Anticipated future interaction menjelaskan bahwa anggota dari suatu online grup akan mengirimkan pesan pesan terhadap satu sama lain secara intens ketika dihadapkan dengan antisipasi pada interaksi di masa depan. Proses komunikasi secara personal akan dilakukan karena komunikator ingin berinteraksi dalam jangka waktu yang lama di masa depan.

b. Chronemics dinyatakan untuk menggambarkan bagaimana individu mempersepsikan waktu dalam berinteraksi secara online. Walther menyimpulkan bahwa fast reply menciptakan kesan yang positif dalam membina hubungan dalam komunikasi online. Tetapi respon yang tertunda (delayed response) dapat megindikasikan sebuah intimate relationship antar kedua pihak karena sudah merasa nyaman dan dekat satu sama lain.

Lebih lanjut dalam penelitian yang dilakukan oleh Tidwell dan Walther menggunakan three-layer categorization yang dikemukakan oleh Altman dan Taylor (1973) untuk mengetahui depth of personal information yang terjadi saat berinteraksi, yaitu:

a. Peripheral layer yaitu biographic data

b. Intermediate layer, terdiri dari attitude, values, opinions

c. Core layer, yang terdiri dari personal beliefs, needs, fears 
Tidwell dan Walther (2002) dalam penelitian ini menemukan bahwa interaksi CMC lebih tinggi dalam menggunakan intermediate questions dibandingkan pada interaksi FtF yang lebih banyak menggunakan peripheral questions sehingga interaksi CMC lebih efektif dalam memperoleh keintiman. Untuk itu, dapat disimpulkan bahwa hubungan akan berkembang menjadi lebih dekat atau lebih jauh berdasarkan pertukaran informasi dan impression yang dibentuk oleh kedua pihak yang berinteraksi. Keintiman dalam suatu hubungan akan dicapai seiring dengan intensitas dan depth dari informasi personal yang terjadi selama berinteraksi.

Lebih lanjut Kark (2012) menyimpulkan bahwa keintiman dalam lingkungan kerja dapat di definisikan sebagai interaksi yang terjadi dalam konteks kerja dan ditandai oleh self-disclosure dan berbagi hal tersebut dengan orang lain serta mampu memahami perasaan orang lain (empati), memiliki pemahaman mendalam, memiliki kepekaan terhadap apa yang penting dan memberikan motivasi untuk berkontribusi dalam kesejahteraan bersama dan kepuasaan. Dari definisi tersebut, keintiman dalam suatu hubungan merupakan hal yang penting untuk dicapai agar dapat memotivasi anggota untuk berkontribusi penuh di sebuah lingkungan kerja. Dalam penelitian ini, hubungan yang intim dapat membantu memotivasi anggota volunter untuk berkontribusi dalam waktu yang lama pada gerakan sosial kesehatan mental yang dilakukan oleh Komunitas Sehatmental.id.

Hasil penelitian yang dilakukan oleh Farrer dan Gavin (2009) mendukung teori social information processing dimana untuk mengenal ketertarikan terhadap satu sama lain, sebagian besar informan menilai isyarat - isyarat tidak langsung seperti cepat lamanya waktu dalam membalas pesan, panjang pendeknya pesan tanggapan, gaya bahasa, tingkat kesopanan serta humor. Selain itu, penelitian ini membuktikan bahwa ada konsep keintiman pada komunikasi online karena hubungan yang awalnya berbasis komputer berlanjut ke text message dan telepon.
Penelitian ini membuktikan bahwa teori social information processing dapat membentuk keintiman walaupun komunikasi hanya dilakukan secara online.

\section{METODE PENELITIAN}

Penelitian ini menggunakan pendekatan kualitatif dengan metode studi kasus. Creswell (2014) mendefinisikan studi kasus adalah penelitian yang digunakan untuk mengembangkan analisis terhadap event, program, aktifitas atau individual secara mendalam. Dalam penelitian ini, metode studi kasus untuk meneliti pola perkembangan hubungan pada individu-individu di Komunitas Sehatmental.id melalui komunikasi online. Informan dalam penelitian dipilih menggunakan teknik snowball sampling. Informan yang dipilih adalah pihak internal dan eksternal Komunitas Sehatmental.id yang memenuhi beberapa kriteria berikut:

Kriteria informan internal dari Komunitas Sehatmental.id:

1. Anggota pengurus komunitas Sehatmental.id

2. Aktif dalam melakukan aktivitas public relations di media sosial Sehatmental.id

3. Berkomunikasi dengan dengan anggota eksternal di media sosial terutama di Instagram@sehatmental.id.

4. Anggota komunitas yang masih berkomunikasi dengan pihak eksternal seperti volunter atau anggota community partner.

Kriteria informan dari eksternal komunitas Sehatmental.id:

1. Mengikuti akun Instagram @ sehatmental.id.

2. Ikut berpartisipasi dalam kegiatan yang dilakukan oleh Sehatmental.id di media sosial (konsultasi online, sharing di Instagram Story, likes, repost dan lainnya) maupun aktivitas offline (event atau talkshow) selama minimal 1 tahun.

3. Pernah atau sedang berpartisipasi sebagai anggota volunter atau 
community partner selama minimal 3 bulan.

4. Masih berkomunikasi dengan anggota internal Komunitas Sehatmental.id Berdasarkan kriteria - kriteria tersebut, diperoleh 7 informan dari Komunitas Sehatmental.id, yaitu:

1. Ade Binarko, founder Komunitas Sehatmental.id.

2. T selaku head of Bandung Komunitas Sehatmental.id

3. $\mathrm{K}$ selaku head of public relations Komunitas Sehatmental.id

4. SIR, volunter Komunitas Sehatmental.id

5. TH, volunter Komunitas Sehatmental.id

6. ET, volunter Komunitas Sehatmental.id

7. VA, community partner Komunitas Sehatmental.id dan founder Komunitas Bipolar Care Indonesia.

Pengumpulan data dilakukan dengan melakukan wawancara mendalam serta data sekunder dari beberapa sumber seperti artikel jurnal, buku dan website. Teknik analisis data menggunakan model Creswell (2014) yang menyatakan bahwa analisis data pada penelitian kualitatif dilakukan untuk memahami data yang diperoleh dengan melakukan pemisahan data dengan melakukan koding.

\section{HASIL DAN PEMBAHASAN}

\section{Analisis Hasil Interaksi Online}

Berdasarkan social information processing theory, hubungan dapat dibangun melalui interpersonal information, impression formation dan relationship development. Interpersonal information Komunitas Sehatmental.id ditunjukkan melalui 3 hal, yaitu identitas komunitas melalui hashtag \#mentalhealth, kredibilitas dan aktivitas komunitas. Dengan menggunakan hashtag \#mentalhealth sebagai identitas komunitas, komunitas dapat menjangkau masyarakat secara luas. Lebih lanjut Walther (dalam Griffin, 2011) menyampaikan bahwa hubungan dapat berkembang dengan menemukan similiarities dimana hashtag \#mentalhealth dapat menjadi salah satu identitas yang menarik atensi masyarakat yang memiliki interest di bidang kesehatan mental untuk bergabung sebagai anggota volunter dan community partner.

Komunitas Sehatmental.id juga menunjukkan kredibilitasnya yang dapat dilihat dengan kesuksesan Mental Health Fest selama 3 tahun terakhir yang berhasil bekerja sama dengan komunitas-komunitas dan narasumber profesional. Mental Health Fest juga menjadi identitas dari Komunitas Sehatmental.id karena ini merupakan festival pertama yang mengangkat tema kesehatan mental yang digagas oleh komunitas nonprofit. Ade Binarko selaku founder Komunitas Sehatmental.id, juga menyampaikan bahwa agar tetap eksis di masyarakat, komunitas harus bisa menyeimbangkan kegiatan di media sosial, kegiatan offline dan kegiatan tahunan yang menjadi identitas dari suatu komunitas.

Komunitas membentuk impression (impression formation) dengan menggunakan bahasa informal seperti "guys" pada konten kontennya. Selain itu, komunitas juga memberikan konten berupa rekomendasi buku, musik dan film seputar kesehatan mental. Komunitas Sehatmental.id menghindari penggunaan istilah-istilah psikologi agar konten dapat mudah dipahami. Selain itu, komunitas juga berinteraksi melalui fitur Instagram Story untuk membentuk impression yang positif seperti membalas reply maupun mentions. Interaksi CMC membutuhkan waktu yang lebih lama (extended time) untuk membentuk kesan satu sama lain, untuk itu komunitas aktif berkomunikasi setiap hari di Instagram melalui posting di feeds maupun Instagram Story. ET, salah satu anggota volunter menambahkan bahwa intensitas komunikasi di Instagram mempunyai peran yang penting dalam pembentukan impression yang positif.

Relationship development ditandai dengan followers yang bergabung menjadi anggota volunter atau community partner. Selain itu, interaksi yang awalnya hanya terjadi di Instagram pun berlanjut ke applikasi 
Whatsapp sehingga lebih personal. Walther (dalam Griffin, 2011) menyatakan bahwa keintiman dalam komunikasi berbasis komputer dapat dilihat dari anticipated future interaction dimana pertukaran pesan secara personal akan dilakukan karena kedua pihak menginginkan interaksi untuk waktu yang lama. Hubungan antar anggota komunitas dengan anggota volunter dan community partner -nya menjadi lebih dekat seiring berjalannya waktu dengan terjadinya pertukaran informasi - informasi personal seperti pertukaran profil anggota, berbagi pengalaman dan bertukar saran. Tetapi informasi personal tersebut digunakan untuk membahas kegiatan komunitas, rencana masa depan komunitas dan pembagian tugas (taskoriented). Kecepatan respon yang diberikan saat berinteraksi pun tidak membuat anggota komunitas merasa lebih dekat satu sama lain. Hasil penelitian berdasarkan three-layer categorization dengan menganalisa depth of personal informations menunjukkan hubungan yang awalnya berada di peripheral layer berlanjut ke intermediate layer yang dilihat dari keterbukaan anggota volunter untuk berbagi pengalaman dan meminta saran antar anggota. Walaupun interaksi berada pada intermediate layer, informasi personal ini tidak mempengaruhi keintiman karena hanya digunakan untuk kepentingan kegiatan komunitas saja. Hal ini kemudian menyebabkan turnover anggota volunter pada Komunitas Sehatmental.id.

Untuk menarik perhatian dari masyarakat, dari sisi konten Komunitas Sehatmental.id mengangkat beberapa nilai sosial yaitu acceptance, openness serta respect others. Menurut Motion, et al (2016) pesan dapat menargetkan publik secara luas dengan mengangkat nilai - nilai sosial. Hal ini menjadi penting karena masih adanya anggapan di masyarakat bahwa membicarakan kesehatan mental adalah hal yang tabu. Selain itu, T selaku head of Bandung region Komunitas Sehatmental.id menyampaikan bahwa akses psikologi masih minim di masyarakat. Untuk itu, komunitas rutin mem - posting konten edukatif untuk memberikan pemahaman mengenai kesehatan mental sehingga masyarakat dapat berani untuk menerima (acceptance) serta terbuka (openness) mengenai kesehatan mental dan tidak judging mengenai pengalaman orang lain (respect others). Namun, dibutuhkan waktu yang lama untuk mengaplikasikan nilai - nilai sosial tersebut karena stigma mengenai kesehatan mental di masyarakat sulit untuk dirubah. Untuk itu, SIR, volunter Komunitas Sehatmental.id berpendapat bahwa informasi adanya komunitas semacam ini harus dilakukan secara konsisten dalam waktu yang panjang untuk dapat dikenal luas di masyarakat.

Menurut Motion, et al (2016), dengan mengkomunikasikan pengalaman yang dialami sehari - hari, pesan yang disampaikan akan lebih mudah dipahami dan diterima. Untuk itu, Komunitas Sehatmental.id mengangkat topik yang relate dalam kehidupan sehari - hari misalnya, konten mengenai stress yang dikaitkan pada kehidupan sehari - hari seperti stress karena masalah pekerjaan, saat mengerjakan skripsi dan hal lainnya. TH sebagai volunter pada divisi social media content menjelaskan, engagement di Instagram semakin meningkat dengan membahas topik tersebut.

Salah satu cara untuk memperkenalkan Komunitas Sehatmental.id adalah dengan menjalin kerja sama dengan opinion leader seperti Tara de Thouars, M.Psi - psikolog, Pingkan Rumondor, M.Psi psikolog dan Ardhito Pramono - musisi yang memiliki ketertarikan dengan isu kesehatan mental. Selain itu, Ade Binarko, founder Komunitas Sehatmental.id juga mencari survivor di bidang kesehatan mental untuk diajak bekerja sama karena pesan yang disampaikan dapat memberikan efek yang positif jika disampaikan oleh survivor dari masalah kesehatan mental itu sendiri. Komunitas Sehatmental.id juga membangun network dengan kesehatan mental lain seperti Bipolar Care Indonesia (BCI), Halo Jiwa, Switch Up, Cinta Setara, Ubah Stigma untuk memperluas gerakan sosialnya.

Sesuai dengan nilai sosial yang
diangkat komunitas yaitu openness,


komunitas memfasilitasi perubahan persepsi tentang kesehatan mental dengan menyediakan free online counseling agar masyarakat dapat berbagi cerita mengenai kesehatan mental dan menyelenggarakan kegiatan free counseling di mall agar masyarakat tidak malu mencari pertolongan profesional. Disampaikan oleh T selaku head of Bandung region bahwa perubahanperubahan ini dapat terlihat dimana semakin banyak followers yang berani untuk berpartisipasi pada fitur QnA di IG Story serta me -repost konten Sehatmental.id pada akun pribadi di Instagram.

Motion, et al (2016) menjelaskan bahwa interaksi yang menggunakan visual dapat memperoleh respon yang positif. Hal ini seperti yang dilakukan oleh Komunitas Sehatmental.id untuk membentuk identitas komunitas yang fun. TH, volunter Komunitas Sehatmental.id menyampaikan bahwa design untuk konten dibuat simple dengan ilustrasi dan mengkombinasikan warna-warna cerah seperti pink, kuning dan biru untuk setiap konten - kontennya.

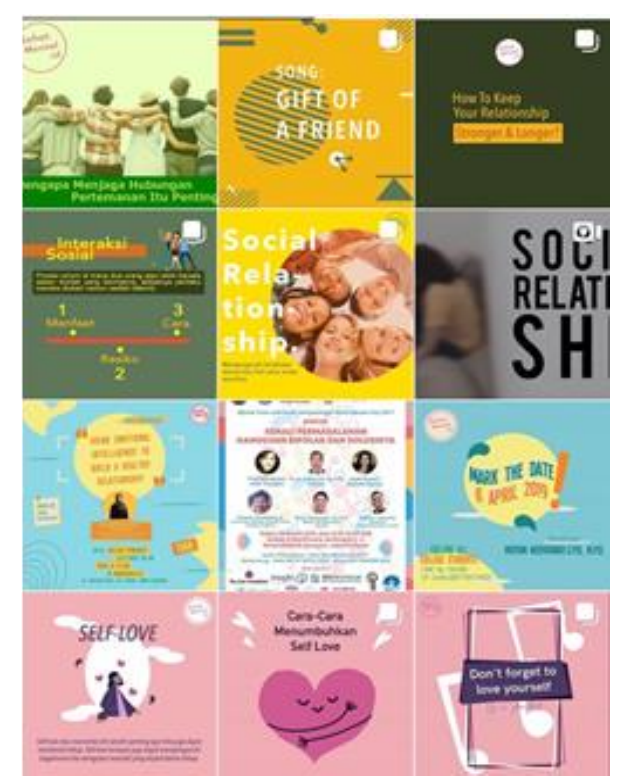

Gambar 3 : Warna Feeds Instagram Sehatmental.id Sumber: Sehat Mental Indonesia, n.d. -b.

Hasil penelitian menunjukkan bahwa panggilan khusus seperti 'Sobat Sehat', katakata 'kita' dan 'kamu' pada caption Instagram memberikan sentuhan yang lebih akrab bagi para followers-nya. Untuk itu, panggilan khusus kepada followers dan kata - kata 'kita' dan 'kamu' dapat digunakan untuk berinteraksi di media sosial.

\section{Keterbatasan Interaksi di Media Sosial}

Dengan memanfaatkan media sosial, pesan dapat disampaikan secara luas, cepat dimana saja dan kapan saja. Namun demikian, media sosial juga memiliki beberapa keterbatasan dalam berinteraksi terutama dalam membina hubungan secara online. Hasil penelitian ini menunjukkan bahwa (1) Ketidakhadiran orang secara fisik menjadi salah satu penyebab interaksi di media sosial menjadi sangat teknis yakni hanya membahas masalah seputar pekerjaan (task-oriented). Anggota komunitas justru dapat mengenal satu sama lain seperti bercanda dan memperhatikan isyarat non-verbal saat interaksi tatap muka berlangsung sehingga hubungan dapat menjadi lebih dekat; (2) Proses pengambilan keputusan menjadi lebih lama melalui media sosial. Hal ini terjadi untuk mengantisipasi missed information antar anggota, maka interaksi harus dilakukan berulang kali secara text-based melalui chatting, email dan direct message di Instagram

\section{PENUTUP}

Berdasarkan kajian pada social information processing theory, keintiman tidak dapat terjadi pada komunitas yang fokusnya hanya kepada task-oriented. Namun sebaliknya, pembentukan keintiman di media sosial dapat tetap terjadi (1) melalui konten yang mengangkat nilai-nilai sosial yang relevan dengan tema komunitas; (2) menggunakan caption yang membangun keterlibatan followers yakni dengan menggunakan kata-kata "kita" dan "kamu"; (3) membuat topik bahasan yang dekat dengan pengalaman sehari-hari anggota komunitas seperti stress kuliah dan putus cinta; (4) Membangun network yang kuat, dalam hal ini meliputi psikolog, survivor dan komunitas kesehatan mental lainnya; serta (5) memfasilitasi adanya kegiatan tatap muka misalnya melalui kegiatan free counseling 
agar perubahan pemahaman anggota tentang pentingnya keberadaan komunitas dapat terjadi lebih permanen.

\section{DAFTAR PUSTAKA}

Bodomo, A. B. (2010). Computer-Mediated Communication for Linguistics and Literacy: Technology and Natural Language Education. Hershey, PA: Information Science Reference (IGI Global)

Choresyo, B., Nulhaqim, S. A. \& Wibowo, H. (2015). Kesadaran Masyarakat Terhadap Penyakit Mental. PROSIDING KS: RISET \& PKM, 2(3), 381 - 387. ISSN: 2442-4480

Creswell, J. W. (2014). Research Design: Qualitative, Quantitative and Mixed Methods Approaches. Thousand Oaks, CA: SAGE Publications Inc.

Farrer, J \& Gavin, J. (2009). Online Dating in Japan: A Test of Social Information Processing Theory. CyberPsychology \& Behaviour, 12(4), 407 - 412. doi: 10.1089/ cpb.2009.0069

Griffin, E. (2011). A First Look at Communication Theory. New York, NY: McGraw-Hill

Kark, R. (2012). Workplace Intimacy in Leader-Follower Relationships. Dalam G. M. Spreitzer \& K. S. Cameron (Eds), The Oxford Handbooks of Positive Organizational Scholarships. Abstrak diperoleh dari https://www.oxfordhandbooks.com/vi ew/10.1093/oxfordhb/978019973461 0.001.0001/oxfordhb9780199734610-e-032

Kementerian Kesehatan Republik Indonesia. (2018). Riset Kesehatan Dasar [PDF File]. Diperoleh dari http://www.depkes.go.id/resources/do wnload/infoterkini/materi_rakorpop_ 2018/Hasil\%20Riskesdas\%202018.pd $\mathrm{f}$
Kementerian Kesehatan Republik Indonesia. (2013). Riset Kesehatan Dasar [PDF File]. Diperoleh dari http://www.depkes.go.id/resources/do wnload/general/Hasil\%20Riskesdas\% 202013.pdf

Motion, J., Heath, R. L. \& Leitch, S. (2016). Social Media and Public Relation Fake friends and powerful public. New York, NY: Routledge

Pang, A., Shin, W., Lew, Z., \& Walther, J. B. (2016). Building relationships through dialogic communication: organizations, stakeholders, and computer-mediated communication. Journal of Marketing Communications, 24(1), 68 - 82. doi: 10.1080/13527266.2016.1269019

Putri, A. W, Wibhawa, B \& Gutama, A. S. (2015). Kesehatan Mental Masyarakat Indonesia (Pengetahuan dan Keterbukaan Masyarakat Terhadap Gangguan Kesehatan Mental). PROSIDING KS: RISET \& PKM, 2(2), 252 - 258. ISSN: 2442-4480

Sehat Mental Indonesia [@sehatmental.id]. (n.d. -a). Followers [Instagram profile]. Diperoleh dari https://www.instagram.com/sehatmen tal.id/

Sehat Mental Indonesia [@sehatmental.id]. (n.d. -b). Posts [Instagram profile]. Diperoleh dari https://www.instagram.com/sehatmen tal.id/

Tidwell, L. C \& Walther, J. B. (2002). Computer-Mediated Communcations Effects on Disclosure, Impressions, and Interpersonal Evaluations Getting to Know One Another a Bit at a Time. Human Communications Research, 28(3), 317 - 348. doi:10.1111/j.14682958.2002.tb00811.x

UU no 36 tahun 2009. (2009, n.d).Tentang Kesehatan. Diperoleh dari http://www.depkes.go.id/resources/do 
72 | Jurnal Komunikasi, Vol. 14 No. 01, Maret 2020: 63-72

wnload/general/UU\%20Nomor\%203

6\%20Tahun2\%20009\%20tentang\%20 Kesehatan.pdf

Walther, J. B. (1992). Interpersonal Effects in Computer-Mediated Interaction A Relational Perspective. Communication Research, 19(1), 52 -
90. doi:10.1177/00936509201900100

World Health Organization. (2018, 30 Maret). Mental Health: strengthening our responses. Diperoleh dari http://www.who.int/news-room/factsheets/detail/mental-healthstrengthening-our-response 